\title{
Antiepileptic Effect of Nux vomica, Homeopathic Remedy, Against Strychnine-Induced Seizers
}

\author{
Anjana Goel ${ }^{1 *}$, Aditya Saxena ${ }^{2}$, Ashok Kumar Bhatia ${ }^{3}$
}

\section{Anjana Goel ${ }^{1 *}$, Aditya Saxena ${ }^{2}$, Ashok Kumar Bhatia $^{3}$}

'Department of Biotechnology, Institute of Applied Sciences and Humanities, GLA University, $17 \mathrm{Km}$ stone, $\mathrm{NH \# 2,}$ Mathura-Delhi Road, PO Chaumuhan, Mathura-281406, (U.P.), INDIA.

${ }^{2}$ Department of Biotechnology, Institute of Applied Sciences and Humanities, GLA University, Mathura, (U.P), INDIA. ${ }^{3}$ Department of Biotechnology, Institute of Applied Sciences and Humanities, GLA University, Mathura, (U.P), INDIA.

\section{Correspondence}

\section{Prof Anjana Goel}

Department of Biotechnology, Institute of Applied Sciences and Humanities, GLA University, $17 \mathrm{Km}$ stone, NH\#2, Mathura-Delhi Road, PO Chaumuhan, Mathura-281406, (U.P.), INDIA.

Phone No: 91-9897006326

E mail Id: anjana.goel@gla.ac.in

\section{History}

- Submission Date: 04-11-2017:

- Review completed: 25-11-2017;

- Accepted Date: 18-12-2017

DOI : 10.5530/pj.2018.2.43

Article Available online

http://www.phcogj.com/v10/i2

\section{Copyright}

(C) 2018 Phcog.Net. This is an openaccess article distributed under the terms of the Creative Commons Attribution 4.0 International license.

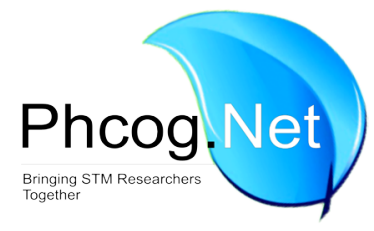

\begin{abstract}
Objective: To investigate the antiepileptic effect of homeopathic remedy Nux vomica on mice and its comparison with standard therapeutic diazepam. Methods: BALB-c mice were taken and divided into three groups comprising ten mice in each group. The first group was treated as control; the second group received standard therapeutics (diazepam, i.p.) and the third group received Nux vomica $\mathrm{CH}$. All groups were treated with strychnine intra peritoneally. Following parameters were observed; start time of convulsions, the number of animals had convulsions, and survival time until death. Results: Nux vomica $\mathrm{CH} 7$ homeopathic preparation was found effective in suspending onset of convulsions $(P<0.01)$, and extending survival time until death $(P<0.01)$ in comparison to control mice. It also increased percentage survival in comparison to control as well as diazepam treated animals. Conclusion: Our study demonstrated efficacy of Nux vomica in epilepsy management.
\end{abstract}

Key words: Nux vomica, Strychnine, Anticonvulsant, Epilepsy.

\section{INTRODUCTION}

Epilepsy affects over 50 million people worldwide, and over 10 million people in India. ${ }^{1}$ its prevalence is about $1 \%$ in Indian population, ${ }^{1}$ which is almost three times higher in rural population compared to the urban population. ${ }^{2}$

Epilepsy includes various neurological disorders in which neuronal activity get disturbed resulting in severe agitation and convulsions. ${ }^{3,4}$ One specific type of convulsions, affecting both hemispheres of the brain is the Tonic-Clonic seizures that include a Tonic phase of $10-30 \mathrm{sec} ;{ }^{5}$ during this period, retrenchment of limbs is observed that is followed by their extension. This phase is followed by a Clonic Phase in which limbs shake in unison.

At the molecular level, epilepsy is attributed to disturbance in Inhibitory Post Synaptic Potential (IPSP) by inhibitory neurons. These neurons use inhibitory neurotransmitters like: Gamma aminobutyric acid (GABA), and glycine. Receptors for both these neurotransmitters are ionotropic receptors containing two binding sites one for the neurotransmitter itself and a $\mathrm{Cl}^{-}$channel. Binding of neurotransmitters to their receptors cause the $\mathrm{Cl}^{-}$channel to open. Opening of the $\mathrm{Cl}^{-}$channel allows a larger number of chloride ions to diffuse inward causing hyperpolarization and an IPSP is generated that inhibit nerve conduction.

Epileptic agent strychnine has been demonstrated to bind and block these receptors and hence inhibits IPSP. It results in contraction of all skeletal muscles, including the diaphragm for extended duration. As a result diaphragm cannot relax, the victim cannot inhale, and suffocation occurs. ${ }^{6}$

Treatment of epilepsy in conventional therapy includes therapeutics like midazolam, lorazepam, phenytoin and diazepam. Diazepam is a medication of the benzodiazepine family that is commonly used to treat a range of conditions including anxiety, alcohol withdrawal syndrome, benzodiazepine withdrawal syndrome, muscle spasms, seizures, trouble sleeping, and restless legs syndrome.

Protective action of diazepam against strychnineinduced seizures is attributed to its positive effect on GABA-mediated IPSC. ${ }^{8}$ but usage of diazepam has been reported to show side effects like sleepiness and trouble with coordination. ${ }^{9}$

Homeopathic system is a holistic system of therapy but since its inception, it received severe criticism from scientific community due to non-measurable amount of drug substance in the homeopathic dose. Still homoeopathy has benefitted globally millions and billions of people, a fact that does not require any citation. In case of epilepsy management, there are several homeopathic remedies reported in scientific publications as well as homeopathic literature..$^{10,11,12,13}$ Homeopathic remedy Nux vomica has also been reported to affect entire gray matter of the Cerebrospinal Nervous System (CNS), especially centering upon tubular gray matter of pons, medulla, and cervical portion of spinal cord. ${ }^{14}$ 


\section{MATERIALS AND METHODS}

\section{Animals}

BALB/c male mice of age 55-60 days, having 24-35 gm weight, were procured from Defense Research and Development Establishment (DRDE) Gwalior, INDIA. Animals were kept at $25 \pm 2^{\circ} \mathrm{C}$ and provided standard pellet diet and water ad libitum. Before conducting the experiments, approval was taken from Institutional Animal Ethical Committee (IAEC), GLA University, Mathura Registration number 1260/ac/09/ CPCSEA.

\section{Chemicals}

Strychnine (SIGMA), Nux vomica 7CH in $40 \%$ alcohol (B. Jain Pharmaceutical Pvt. Ltd) and diazepam (ALPA Laboratories $L t d)$ were procured and used in this study. Selection of Nux vomica potency $\mathrm{CH} 7$ was based on the previous study of Alecu et al. ${ }^{12}$

\section{Determination of nontoxic route of Nux vomica administration}

6 animals were taken and divided into two groups: In the first group, $50 \mu \mathrm{l}$ Nux vomica homeopathic preparations was given intraperitoneally while in the second group it was given sublingual orally. All animals died within 10-15 min after intraperitoneal injection while no change was observed in the oral group. Thus, oral administration of Nux vomica was used for further pharmacological studies.

\section{Effect of Nux vomica on strychnine induced convulsion}

$30 \mathrm{BALB} / \mathrm{c}$ male mice, without associated pathology, were divided them into 3 groups of 10 animals each. All the mice were kept on overnight fasting before conducting the experiment. In all the groups strychnine poisoning was caused by administering strychnine $0.8 \mathrm{mg} / \mathrm{kg}$ body weight intraperitoneally and following protocol was designed according to the standard procedure. ${ }^{15}$

\section{Group 1}

This group was treated as negative control group; it received saline intraperitoneally as placebo $1 \mathrm{~h}$ before administration of strychnine and $40 \%$ $\mathrm{v} / \mathrm{v}$ alcohol immediately after it orally.

Saline $\rightarrow$ strychnine $\rightarrow$ alcohol $(40 \% \mathrm{v} / \mathrm{v})$

(Placebo) $1 \mathrm{~h}$ (gavages)

\section{Group 2}

It was positive control group; it received diazepam (standard therapeutic) $5 \mathrm{mg} / \mathrm{kg}$ body weight intraperitoneally $1 \mathrm{~h}$ before administration of strychnine and $40 \% \mathrm{v} / \mathrm{v}$ alcohol immediately after it.

Diazepam $\rightarrow$ strychnine $\rightarrow$ alcohol $(40 \% \mathrm{v} / \mathrm{v})$

(Standard therapeutic) $1 \mathrm{~h}$ (gavages)

\section{Group 3}

This group was treated as experimental group and received homeopathic remedy Nux vomica $(\mathrm{CH} 7)$ orally immediately after strychnine poisoning. Saline $\rightarrow$ strychnine $\rightarrow$ Nux vomica

(Placebo) $1 \mathrm{~h}$ (gavages)

Immediately after the administration of strychnine, animals were observed for the following symptoms

Start time of convulsions,

Number of animals had convulsions,

Survival time until death,
Mortality in animals.

\section{Statistical analysis}

Data were expressed as mean \pm SEM and analyzed by One-Way ANOVA (Dunnet test) using Graph Pad Prism, version 5.01. $\mathrm{P}<0.05$ was considered as statistically significant.

\section{RESULTS}

In our study diazepam, standard medicine was given intraperitoneally while Nux vomica was given orally as the alcoholic preparation of Nux vomica was found to be lethal when administered intraperitoneally due to the presence of alcohol in the preparation.

\section{Effect of Nux vomica on strychnine induced convulsions}

The average time for the onset of convulsions was 4.448 \pm 0.437 , $8.196 \pm 0.697$ and $7.673 \pm 0.766 \mathrm{~min} \pm$ SEM in control, diazepam and Nux vomica treated groups respectively (Figure 1 ). Nux vomica significantly $\left(\mathrm{p}<0.01^{\star *}\right)$ prolonged the onset of convulsions induced by strychnine. In diazepam group the convulsion time was extended to an extremely significant value of $\mathrm{p}<0.001^{\star * \star}$. However when Nux vomica group was compared with diazepam group than the $P$-value was found non-significant $(\mathrm{p}>0.05)$

\section{Effect of Nux vomica on strychnine induced death}

$100 \%$ death was observed in the negative control group while $30 \%$ and $20 \%$ recovery was observed in Nux vomica and diazepam treated groups respectively. In Nux vomica treated animals \% protection was higher than diazepam treated animals (Figure 2).

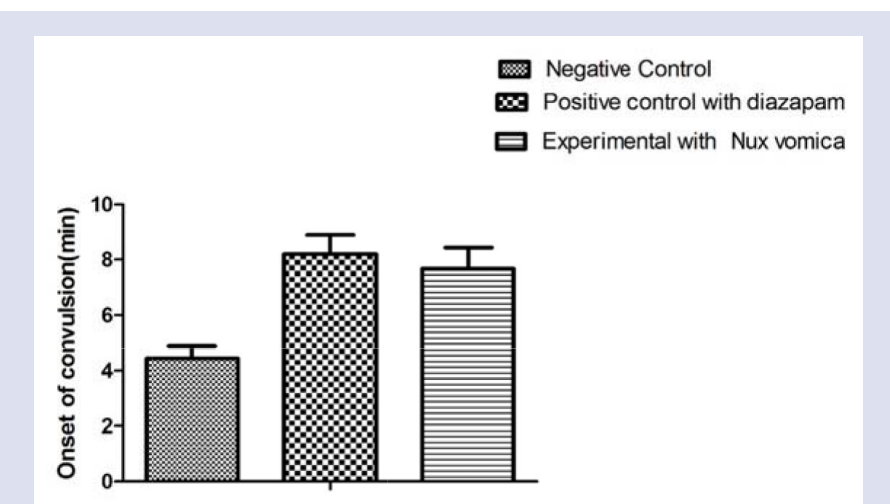

Figure 1: Effect of Nux vomica on strychnine induced convulsions.

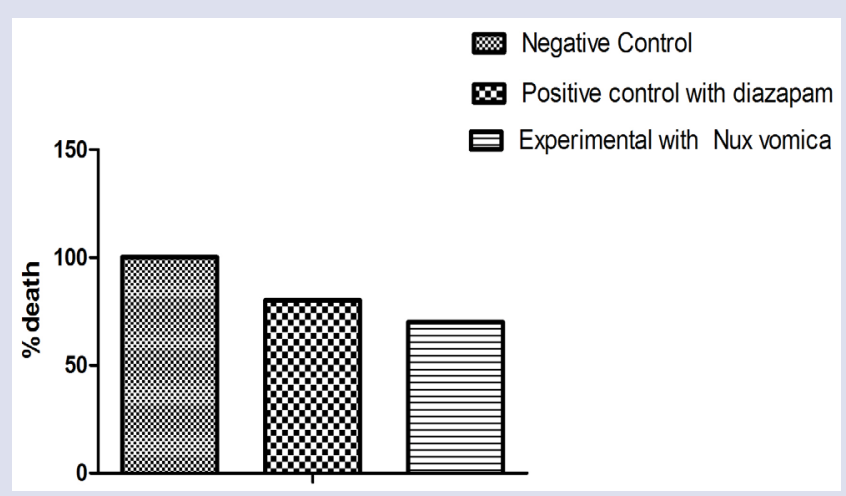

Figure 2: Effect of Nux vomica on strychnine induced death. 


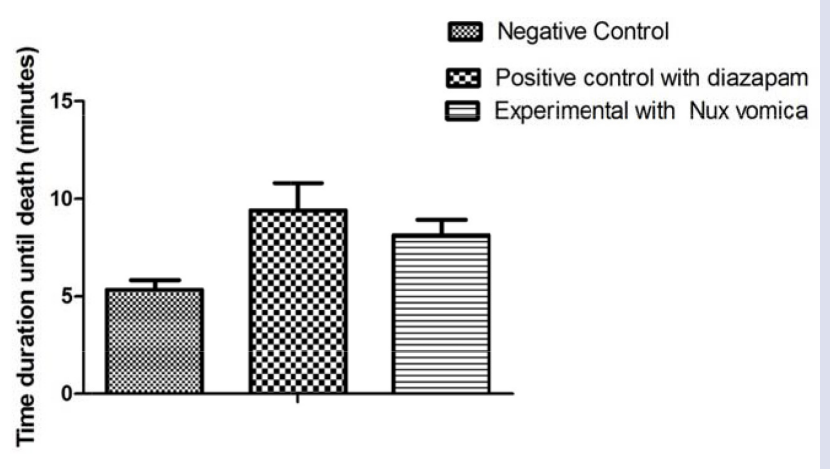

Figure 3: Effect of Nux vomica on time duration until death. medicines act through modulation of gene expression. Our present study is the first step toward this objective.

\section{CONCLUSION}

Results of our study clearly indicate the efficacy of Nux vomica on strychnine induced neurological disorder leading to death. It was found statistically significant in protecting the animals. Our study opens an area for further research for the mechanism of action of this medicine.

\section{ACKNOLEDGEMENT}

Financial support by Ministry of AYUSH, Govt. of India, New Delhi is duly acknowledged. We are grateful to Dr Geeta Rani Arora, B. Jain Pharmaceutical Pvt. Ltd. New Delhi, for providing the homoeopathic preparation of Nux vomica $\mathrm{CH} 7$ for the experiments. The authors are highly thankful to Vice Chancellor, and Director, IAH, GLA University, Mathura for providing infrastructure and animal house facility.

\section{CONFLICT OF INTEREST}

Authors have no conflict of interest.

\section{ABBREVIATIONS USED}

IPSP: Inhibitory Post Synaptic Potential; GABA: Gamma aminobutyric acid.

\section{REFERENCES}

\section{DISCUSSION}

Diazepam acts as a positive allosteric modulator of GABA, it is administered as pretreatment. As it was not known whether Nux vomica is more effective as prophylactic or therapeutic, therefore, it was given as post treatment of strychnine. Probable mode of action of homeopathic medicines might be gene expression modulation, through signal transduction pathways. Due to the ultra-high dilution, it is more likely that homeopathic medicines act as physical signal rather than a chemical signal to invoke these signal transduction pathways. ${ }^{16}$ Our experiment clearly demonstrated that Nux vomica $\mathrm{CH} 7$ was significantly more effective in delaying and even preventing seizures caused by strychnine in comparison to control animals; time to death was also extended significantly in Nux vomica treated group in comparison to control treated animals. The protective action of Nux vomica was found to be stronger than diazepam. \% survival was $10 \%$ higher in Nux vomica treated animals as compared to diazepam group.

Research in homeopathy is a challenging task owing to lack of proper understanding of Modus-operandi of homeopathic medicines in accordance with "Law of Similia". Another problem that comes into way is "Law of the Minimum Dose and Potentization" that makes it difficult to conduct pharmacodynamics and pharmacokinetics studies due to the use of ultra-high dilutions beyond Avogadro number. Animal experimentation poses a further challenge in devising strategies to incorporate, "Law of Individualization" of Homoeopathy in study design. All these facts may account to poor reproducibility of experimental results across similar studies. We hypothesize that probable path toward the elucidation of the mechanism of action of homoeopathy should follow the steps; 1. Repeated animal experiments to verify the efficacy of a particular medicine against a disease and 2. Formulating strategies to analyze transcriptome profiles between case-control groups as it has been reported previously that transcription inhibitors, Actinomycin D counters effect of homoeopathic medicines. ${ }^{17,18}$ so it is highly likely that homeopathic
1. Sridharan R, Murthy BN. Prevalence and pattern of epilepsy in India. Epilepsia. 1999;40(5):631-6.

2. Leonardi M, Ustun TB. The global burden of epilepsy. Epilepsia. 2002;43(6):21-5

3. Chang BS, Lowenstein DH. Epilepsy. N. Engl. J. Med. 2003;349(13):1257-66.

4. Fisher RS, Acevedo C, Arzimanoglou A, Bogacz A, Cross JH, Elger CE et al. ILAE Official Report: A practical clinical definition of epilepsy Epilepsia. 2014;55(4):475-82.

5. Ramsay R, Detoledo J. Tonic-clonic seizures: a systematic review of antiepilepsy drug efficacy and safety. Clinical Therapeutics. 1997;19(3):433-46.

6. Tortora GJ, Derrickson BH. Principles of anatomy and physiology, $12^{\text {th }}$ Edition. Chichester: Wiley. 2008;447.

7. Riss J, Cloyd J, Gates J, Collins S. Benzodiazepines in epilepsy: pharmacology and pharmacokinetics. Acta Neurologica Scandinavica. 2008;118(2):69-86.

8. Pericic D, Manev H, Boranic M, Poljak-Blaži M, Lakic N. Effect of Diazepam on Brain Neurotransmitters, Plasma Corticosterone, and the Immune System of Stressed Rats. Annals of the New York Academy of Sciences. 1987;496(1):450-8.

9. Schweizer E, Rickels K. Benzodiazepine dependence and withdrawal: a review of the syndrome and its clinical management. Acta Psychiatrica Scandinavica. 1998;98(s393):95-101.

10. Varshney JP. Clinical management of idiopathic epilepsy in dogs with homeopathic Belladonna 200C: a case series. Homoeopathy. 2007;96(1):46-8.

11. Gosavi TP, Kandhare AD, Ghosh P, Bodhankar SL. Anticonvulsant activity of Argentum metallicum, a homeopathic preparation. Der Pharmacia Letter. 2012;4(2):626-37.

12. Alecu A, Alecu M, Brezeanu R, Marcus G, Cojacaru A. Designs for research 2011;10(35):80.

13. Lilienthal S. Homeopathic Therapeutics, B. Jain Publishers. 1985;233.

14. Burt WH. Physiological Materia Medica B. Jain Publishers. 2003;644

15. Vogel HG. Drug Discovery and Evaluation: Pharmacological Assays, 3rd Edition. 2008;52(1):47.

16. Khuda-Bukhsh AR. To wards understanding molecular mechanisms of action of homeopathic drugs: An overview. Mol Cellular Biochem. 2003;253(1):339-45.

17. Datta S, Mallick P, Khuda-Bukhsh AR. Efficacy of a potentized homeopathic drug in reducing genotoxic effects produced by arsenic trioxide in mice: II. Comparative efficacy of an antibiotic, Actinomycin D alone and in combination with either of two microdoses. Comp Ther Med. 1999;7:156-75.

18. Chakrabarti J, Biswas SJ, Khuda-Bukhsh AR: Cytogenetical effects of ultrasound in mice and their modulations by Actinomycin FD and a homeopathic drug, Arnica-30. Indian J Exp Biol. 2001;39:123-4. of High Dilutions in animal models: an update. Int $\mathrm{J}$ High Dilution Res. 
GRAPHICAL ABSTRACT

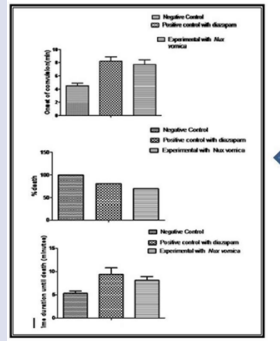

Results

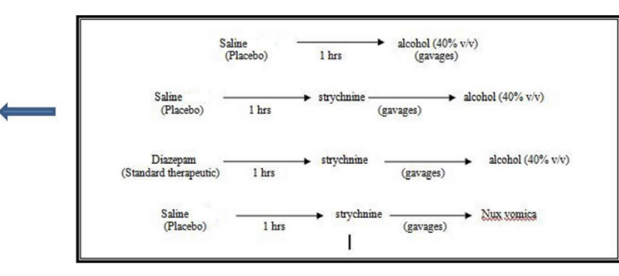

Pharmacological experiment for evaluation of efficacy of Nux vomica

\section{SUMMARY}

- The present study has highlighted the efficacy of homeopathic medicine. Nux vomica, on strychnine induced seizers. The mode of action of this drug might be through the modulation of gene expression at nano levels. Further gene sequence analysis may explore the action mechanism of this drug.

\section{ABOUT AUTHORS}

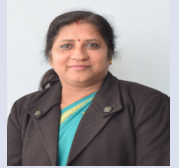

Dr. Anjana Goel: Has done her Ph.D. from Central Drug Research Institute, Lucknow. Currently she is working as Associate Professor, Dept of Biotechnology, GLA University, Mathura.

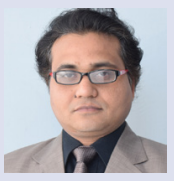

Mr Aditya Saxena: Is M.Sc, M.Tech(Bioinformatics). He is Assistant Professor in Dept of Biotechnology, GLA University, Mathura.

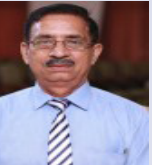

Prof A.K. Bhatia: Is Head of the Biotechnology dept in the same university. He has vast experience of teaching and Research. He is M.V.Sc; Ph.D. in Microbiology.

Cite this article: Goel A, Saxena A, Bhatia AK. Antiepileptic Effect of Nux Vomica, Homeopathic Remedy, Against StrychnineInduced Seizers. Pharmacog J. 2018;10(2):245-8. 